\title{
Does the Early and Late Rate of Torque Development, Change in Relation to the Quadriceps Angle?
}

\author{
Ajlan Saç \\ Correspondance: Ajlan Saç, School of Physical Education and Sports, Trakya University, Edirne, 22030, Turkey.
}

Received: December 26, 2018

Accepted: January 29, 2019 Online Published: January 30, 2019

doi:10.11114/jets.v7i3S.4003

URL: https://doi.org/10.11114/jets.v7i3S.4003

\begin{abstract}
The rate of torque development (RTD), which determines the force that can be developed in the early phase of muscle contraction $(0-200 \mathrm{~ms})$, is very important in terms of tracking explosive strength improvement and preventing knee injuries. The purpose of this study was to investigate the relationship of quadriceps angle which affects the structural alignment of the lower extremity with early $(0-100 \mathrm{~ms})$ and late $(100-200 \mathrm{~ms})$ rate of torque development of the knee extensor muscles and myoelectrical activity. The study was carried out with 38 well-trained male basketball players (mean age: $22.3 \pm 2.5$ years). The participants were divided into two groups with normal $\left(<11^{\circ}\right)$ and abnormal $\left(>10^{\circ}\right)$ values. RTD was measured in concentric/concentric mode at 60,120 and $180 \%$ s angular velocities in an isokinetic dynamometer. Surface electromyography (sEMG) was used to determine the myoelectrical activity. When $\mathrm{RTD}_{0-100}$ and $\mathrm{RTD}_{100-200}$ were examined, statistically significant difference was observed at 60 and $120 \% \mathrm{~s}(\mathrm{p}<0.05)$. However, no difference was observed at $180 \%$ s. In addition, sEMG data did not have a statistically significant difference between groups. Negative correlation was found between all RTD at 60,10 and $180 \%$ with Q angle $\left(180^{\circ} / \mathrm{RTD}_{0-100} \mathrm{r}=-0.34\right.$, $180 \% \mathrm{RTD}_{100-200} \mathrm{r}=-0.35,120^{\circ} / \mathrm{s} \mathrm{RTD}_{0-100} \mathrm{r}=-0.40,120^{\circ} / \mathrm{sTD}_{100-200} \mathrm{r}=-0.48,60 \% \mathrm{RTD}_{0-100} \mathrm{r}=-0.55,60^{\circ} / \mathrm{s}$ $\left.\mathrm{RTD}_{100-200} \mathrm{r}=-0.59 ; \mathrm{p}<0.05\right)$. There was a negative correlation between the structural differences of the lower extremity and the early and late rate of torque development of the knee extensor muscles. Considering the structural variables, it is thought that it is important to improve the rate of torque development with appropriate resistance training in athletes with variables such as abnormal Q angle, and thus knee injuries can be prevented through athletic development.
\end{abstract}

Keywords: electromyography, explosive strength, Isokinetics, lower extremity, quadriceps angle, rate of torque development

\section{Introduction}

Rate of torque development (RTD) is a measure of the explosive strength, or simply how fast an athlete can develop torque - hence the 'rate' of 'torque development'. This can be also defined as the rate of torque development of the contractile elements (Aagaard, Simonsen, Andersen, Magnusson, \& Dyhre-Poulsen, 2002). Research shows that the RTD is directly related to performance in physical activities such as jumping, sprint, cycling, and weightlifting, moreover, higher athletic performances can be achieved through improvements of RTD (Laffaye \& Wagner, 2013; Nuzzo, McBride, Cormie, \& McCaulley, 2008; Slawinski et al., 2010).

The rate of torque development, which is the main determinant of the force exerted by the explosive limb movements that require quickness, is a very important parameter for the functional evaluation of the torque generation capacity and rapid muscle contractions (Freire et al., 2015). Examining the torque/time ratio, which is neuromuscular performance parameter is a widely used method when evaluating the explosive strength (Aagaard et al., 2002). When moving, to be able to ensure the durability of the (rate of torque values) play huge role in order to prevent the injuries which can be caused by the mechanical reasons (Morel et al., 2015).

RTD is calculated as the slope of the torque-time curve ( $\Delta$ torque/ $\Delta$ time). Typically, maximal muscle torque is produced at 300 milliseconds time-window after onset of contraction (Thorstensson, Karlsson, Vitasalo, Luhtanen, \& Komi, 1976). . In some sports branches, such as 110-160 ms in the long jump, 180-220 ms in the high jump and 80-120 ms in the sprint, it is observed that the maximum muscle torque developments occurs within a less than $300 \mathrm{~ms}$, but in activities such as walking and hiking, require torque to be produced in shorter time intervals but do not require maximal effort. Therefore, RTD is more important in terms of performance and physical functionality than maximum muscle strength (Maffiuletti et al., 2016; Tillin, Pain, \& Folland, 2013). The smallest development that may occur in RTD is 
gaining importance in order to reveal greater muscle strength values in the first phase of muscle contraction (0-200 ms). In many studies, considering the functional movement, and patient reports, attention was drawn to the importance of RTD rather than the maximal strength on the lower extremity (Allen, Sherrington, Canning, \& Fung, 2010; Bento, Pereira, Ugrinowitsch, \& Rodacki, 2010; Clark et al., 2010; Holsgaard-Larsen, Caserotti, Puggaard, \& Aagaard, 2011).

As we all know, there are many structural and physiological variables affecting athletic performance. One of the most important structural and biomechanical variables affecting the performance of the lower extremity is the quadriceps angle ( $\mathrm{Q}$ angle). The $\mathrm{Q}$ angle is an important parameter to assess patellofemoral mechanics and is thus of great interest to clinicians. It is a clinical measure of the alignment of the quadriceps femoris musculature relative to the alignment of the underlying skeletal structures of the pelvis, femur and tibia (Livingston, 1998). It was first defined by Brattstrom (Brattström, 1964) as an angle formed between the ligamentum patellae and the extension of the line formed by the quadriceps femoris muscle resultant force with its apex at the patella. According to studies, larger than normal Q angle values are the reason that the neuromuscular response and the reflex of the quadriceps increase and the explosive power and vertical jump power decrease (Chester et al., 2008; Witvrouw, Lysens, Bellemans, Cambier, \& Vanderstraeten, 2000).

The RTD, which is one of the determinants of the explosive power is influenced by muscle cross-sectional area, stiffness of the muscle-tendon complex and fiber-type composition (Harridge et al., 1996) well as the neuromechanical factors such as motor unit recruitment and firing frequency (Maffiuletti et al., 2016). Thus, changing RTD values directly affect performance.

Many studies on the factors affecting the RTD do exist in the literature, but no study has been found to investigate the effect of lower extremity anatomic structural alignment on RTD. Therefore, the aim of this study is to investigate the relationship between early $(0-100 \mathrm{~ms})$ and late $(100-200 \mathrm{~ms})$ torque development rates of knee extensor muscle and Q angle which is one of the factors affecting the lower extremity structural alignment of myoelectric activities.

\section{Method}

2.1 Subjects

Thirty-eight well trained male basketball players volunteered to participate in this study. Descriptive data of the subjects are presented in Table 1. The inclusion criteria were: a) having an active team sports license b) had no pre-existing injury or surgery c) having right-leg dominance. The study was conducted in accordance the Declaration of Helsinki.

Table 1. Demographic characteristics of the participants

\begin{tabular}{lccccc}
\hline & $\begin{array}{c}\mathbf{Q} \text { angle }<\mathbf{1 1}^{\circ} \\
(\mathbf{n}=\mathbf{1 9})\end{array}$ & $\begin{array}{c}\mathbf{Q} \text { angle }>\mathbf{1 0}^{\circ} \\
(\mathbf{n = 1 9 )}\end{array}$ & $\mathbf{t}$ & df & $\mathbf{p}$ \\
\hline Age (years) & $22.16 \pm 2.77$ & $22.37 \pm 2.24$ & -0.257 & 36 & 0,798 \\
Height (cm) & $183.63 \pm 8.08$ & $171.42 \pm 5.42$ & 0.990 & 36 & 0,329 \\
Mass (kg) & $81 \pm 6.42$ & $74.42 \pm 11,09$ & 2.238 & 36 & 0,032 \\
$\mathbf{Q}$ angle $\left({ }^{\circ}\right)$ & $7.79 \pm 1.47$ & $19.89 \pm 3.79$ & -12.948 & 36 & $<0,001$ \\
\hline
\end{tabular}

Values are expressed as mean $\pm \mathrm{SD}$.

\section{$2.2 Q$ angle Measurements}

The $\mathrm{Q}$ angle was measured using a manual gonimetric method which has high correlation with magnetic resonance imaging (MRI) technique. In the standing position, the participants faced forward and aligned the longitudinal axis of the foot, with the quadriceps in a relaxed state, and with equal load on each foot. It was ensured that the second digit and mid-heel were aligned perpendicular to the coronal plane. The goniometer's pivot point was placed in the center of the patella; the stationary arm was aligned with the tibia tubercle, and the moving arm was aligned with anterior inferior iliac spine. Subjects were divided into two groups: group 1, Q angle $<11^{\circ}$; group 2, Q angle $>10^{\circ}$.

\subsection{Surface EMG (sEMG) Recording}

sEMG was recorded from $\mathrm{m}$. vastus medialis (VM), m. vastus lateralis (VL) ve m. rectus femoris (RF) during isokinetic tests. $\mathrm{Ag} / \mathrm{AgCI}$ bipolar surface electrodes were applied to lightly abraded, washed skin over the respective muscle belly, parallel to pennation angle. Each electrode was adhered to skin with soft medical adhesive plaster in case oscillation caused the electrode to drift awat from the skin during isokinetic tests. sEMG electrode placement for each muscle was done according to European recommendations for the noninvasive assessment of muscles for surface electromyography (Hermens, Freriks, Disselhorst-Klug, \& Rau, 2000). 
The muscle activity responses were recorded using 16-channel portable sEMG device (Biomonitor ME6000, Mega Electronics Ltd., Kuopio, Finland). The sEMG signal was sampled at $2000 \mathrm{~Hz}$ and preamplified by a gain of $1000 \mathrm{~Hz}$. A normalization process was performed in order to determine the sEMG values (root-meansqaure, RMS). sEMG data processing was performed using MegaWin 3.0 software (Mega Electronics Ltd., Kuopio, Finland).

\subsection{Isokinetic Test Procedure}

The isokinetic test was performed using a Humac Norm dynamometer and the data were collected with Humac2009 v10 software (CSMI, Stoughton, Massachusetts, USA). Before beginning the isokinetic test, a five-min warm up exercise on a cycle ergometer was done to keep the athletes' heart rates between 100 and 120 beats per min. To allow participants to be able to sit comfortably, the dynamometer seat's back support was adjusted at a hip-joint angle of $85^{\circ}\left(0^{\circ}=\right.$ full extension). At the extremity being measured, knee adaptors were placed at approximately 2 to $3 \mathrm{~cm}$ proximal to the dorsal surface of the foot. During measurement, to stabilise and isolate the entire body, the chest, pelvis and femoral arches were kept stationary with straps. To avoid contralateral extremity movement, the ankles were secured by stabilizing them underneath the chair.

To familiarize the participants with the isokinetic dynamometer isokinetic contractions were done with angular velocities of 240 and $300 \%$ s. For adaptation, each participant performed 15 maximal concentric extension and flexion with 45-s rest between velocities, which included a two-min resting period before the test. After the adaptation period, each participant completed five maximal repetitions at $60,120,180 \%$ s. One-min rest periods were allowed between repetitions. All participants were given encouragement for their efforts throughout the test. The onset of muscle contraction was defined as the time point which the torque curve exceeded the baseline by $>7.5 \mathrm{Nm}$ (Blazevich, Horne, Cannavan, Coleman, \& Aagaard, 2008). RTD measurements were calculated by the Humac2009 v10 software (HUMAC2009, CSMi, Stoughton, MA). All RTD values were normalized by body weight.

\section{Results}

\subsection{Statistics and Data Analysis}

Statistical analyses were performed using the IBM SPSS version 20.0 software (IBM Corp., Armonk, NY, USA). Descriptive data were expressed in mean and standard deviation. The normality of the data was tested using the Shapiro-Wilk test, and the results showed normal distribution. An Independent Samples t-test was used for statistical comparisons. The statistical relationship between variables was confirmed using the Pearson's correlation analysis. A p value of $<0.05$ was considered statistically significant.

When $\mathrm{RTD}_{0-100}$ and $\mathrm{RTD}_{100-200}$ were examined, statistically significant difference was observed at 60 and $120^{\circ} \mathrm{s}$ $(\mathrm{p}<0.05)$. However, no difference was observed at $180 \%$ s (Table 2). In addition, sEMG data do not have a statistically significant difference between groups (Table 3). Negative correlation was found between all RTD at 60, 10 and $180^{\circ} / \mathrm{s}$ with Q angle $\left(180^{\circ} / \mathrm{sTD}_{0-100} \mathrm{r}=-0.34,180 \% \mathrm{RTD}_{100-200} \mathrm{r}=-0.35,120 \% \mathrm{RTD}_{0-100} \mathrm{r}=-0.40,120 \% \mathrm{RTD}_{100-200} \mathrm{r}=-0.48\right.$, $\left.60 \% \mathrm{RTD}_{0-100} \mathrm{r}=-0.55,60 \% \mathrm{RTD}_{100-200} \mathrm{r}=-0.59 ; \mathrm{p}<0.05\right)($ Table 4$)$.

Table 2. The early and late rate of torque development values at three different velocities in $\left\langle 11^{\circ}\right.$ and $>10^{\circ} \mathrm{Q}$ angle groups

\begin{tabular}{|c|c|c|c|c|c|c|c|}
\hline & & & $\begin{array}{c}Q \text { angle }<11^{\circ} \\
(n=19)\end{array}$ & $\begin{array}{c}Q \text { angle }>10^{\circ} \\
(n=19)\end{array}$ & $\mathbf{t}$ & df & $\mathbf{p}$ \\
\hline \multirow{6}{*}{ RTD (Nm) } & \multirow{2}{*}{$180^{\circ} / \mathrm{s}$} & 0-100 ms & $107.91 \pm 52.75$ & $85.22 \pm 32.11$ & 1.602 & 36 & 0.118 \\
\hline & & $100-200 \mathrm{~ms}$ & $82.59 \pm 35.03$ & $66.26 \pm 40.64$ & 1.326 & 36 & 0.193 \\
\hline & \multirow{2}{*}{$120^{\circ} / \mathrm{s}$} & 0-100 ms & $179.94 \pm 72.9$ & $106.5 \pm 56.83$ & 2.992 & 36 & $0.005^{*}$ \\
\hline & & $100-200 \mathrm{~ms}$ & $168.22 \pm 102.95$ & $99.51 \pm 31.82$ & 3.184 & 36 & $0.003^{*}$ \\
\hline & \multirow{2}{*}{$60 \% / s$} & 0-100 ms & $143.45 \pm 59.6$ & $96.14 \pm 50.91$ & 2.631 & 36 & $0.012 *$ \\
\hline & & $100-200 \mathrm{~ms}$ & $114.67 \pm 44.04$ & $68.13 \pm 35.15$ & 3.600 & 36 & $0.001 *$ \\
\hline
\end{tabular}

Values are expressed as mean \pm SD.

$* \mathrm{p}<0.05$ 
Table 3. The myoelectrical activity values at $0-100$ and $100-200 \mathrm{~ms}$ in $\left\langle 11^{\circ}\right.$ and $>10^{\circ} \mathrm{Q}$ angle groups

\begin{tabular}{|c|c|c|c|c|c|c|c|}
\hline & & & $\begin{array}{c}Q \text { angle }<11^{\circ} \\
(n=19)\end{array}$ & $\begin{array}{c}Q \text { angle }>10^{\circ} \\
(n=19)\end{array}$ & $\mathbf{t}$ & df & $\mathbf{p}$ \\
\hline \multirow{6}{*}{$180^{\circ} / \mathrm{s}$} & \multirow{2}{*}{$\mathbf{V M}(\mathbf{m V})$} & 0-100 ms & $225.73 \pm 116.83$ & $132.42 \pm 102.6$ & 1.616 & 36 & 0.073 \\
\hline & & $100-200 \mathrm{~ms}$ & $174.85 \pm 155.85$ & $179.17 \pm 195.84$ & -0.080 & 36 & 0.937 \\
\hline & \multirow{2}{*}{$\mathbf{V L}(\mathbf{m V})$} & 0-100 ms & $170.6 \pm 131.72$ & $134.79 \pm 111.16$ & 0.905 & 36 & 0.371 \\
\hline & & $100-200 \mathrm{~ms}$ & $248.84 \pm 169.92$ & $164.84 \pm 185.18$ & 1.457 & 36 & 0.154 \\
\hline & \multirow{2}{*}{ RF (mv) } & 0-100 ms & $205.54 \pm 120 \pm 12$ & $168.31 \pm 175.94$ & 0.762 & 36 & 0.451 \\
\hline & & $100-200 \mathrm{~ms}$ & $180.97 \pm 135.08$ & $188.79 \pm 117.29$ & -0.191 & 36 & 0.850 \\
\hline \multirow{6}{*}{$120 \% / s$} & \multirow{2}{*}{ VM (mv) } & $0-100 \mathrm{~ms}$ & $252.86 \pm 126.34$ & $171.36 \pm 139 \pm 67$ & 1.886 & 36 & 0.067 \\
\hline & & $100-200 \mathrm{~ms}$ & $160.96 \pm 112.35$ & $191.39 \pm 142.56$ & -0.731 & 36 & 0.470 \\
\hline & \multirow{2}{*}{ VL (mV) } & 0-100 ms & $177.89 \pm 138.52$ & $160.51 \pm 130.42$ & 0.398 & 36 & 0.693 \\
\hline & & $100-200 \mathrm{~ms}$ & $264.33 \pm 208.64$ & $259.06 \pm 211.38$ & 0.077 & 36 & 0.939 \\
\hline & \multirow{2}{*}{$\mathbf{R F}(\mathbf{m V})$} & 0-100 ms & $206.70 \pm 122.59$ & $173.62 \pm 212.56$ & 0.588 & 36 & 0.560 \\
\hline & & $100-200 \mathrm{~ms}$ & $240.60 \pm 258.77$ & $171.34 \pm 153.13$ & 1.004 & 36 & 0.322 \\
\hline \multirow{6}{*}{$60^{\circ} / \mathrm{s}$} & \multirow{2}{*}{ VM (mV) } & 0-100 ms & $225.42 \pm 156.39$ & $189.34 \pm 142.11$ & 0.744 & 36 & 0.462 \\
\hline & & $100-200 \mathrm{~ms}$ & $208.32 \pm 202.45$ & $186.97 \pm 173.69$ & 0.349 & 36 & 0.729 \\
\hline & \multirow{2}{*}{ VL (mV) } & 0-100 ms & $238.13 \pm 183.43$ & $183.77 \pm 151.66$ & 0.996 & 36 & 0.326 \\
\hline & & $100-200 \mathrm{~ms}$ & $283.36 \pm 195.58$ & $207.73 \pm 181.48$ & 1.236 & 36 & 0.225 \\
\hline & \multirow{2}{*}{$\mathbf{R F}(\mathbf{m V})$} & 0-100 ms & $214.18 \pm 194.04$ & $126.19 \pm 100.75$ & 1.754 & 36 & 0.088 \\
\hline & & $100-200 \mathrm{~ms}$ & $228.33 \pm 154.91$ & $206.27 \pm 189.07$ & 0.394 & 36 & 0.696 \\
\hline
\end{tabular}

Values are expressed as mean \pm SD.

$* \mathrm{p}<0.05$

Table 4. Correlation coefficients between Q angle and early and late rate of torque development, myoelectrical activity at three different velocities

\begin{tabular}{|c|c|c|c|c|c|c|c|c|c|c|c|c|}
\hline \multirow{4}{*}{$\begin{array}{l}\text { RTD } \\
\text { (Nm) }\end{array}$} & \multicolumn{4}{|c|}{$180^{\circ} / \mathrm{s}$} & \multicolumn{4}{|c|}{$120^{\circ} / \mathrm{s}$} & \multicolumn{4}{|c|}{$60^{\circ} / \mathrm{s}$} \\
\hline & \multicolumn{2}{|c|}{ 0-100 ms } & \multicolumn{2}{|c|}{$100-200 \mathrm{~ms}$} & \multicolumn{2}{|c|}{ 0-100 ms } & \multicolumn{2}{|c|}{$100-200 \mathrm{~ms}$} & \multicolumn{2}{|c|}{ 0-100 ms } & \multicolumn{2}{|c|}{$100-200 \mathrm{~ms}$} \\
\hline & $\mathbf{r}$ & $\mathbf{p}$ & $\mathbf{r}$ & $\mathbf{p}$ & $\mathbf{r}$ & $\mathbf{p}$ & $\mathbf{r}$ & $\mathbf{p}$ & $\mathbf{r}$ & $\mathbf{p}$ & $\mathbf{r}$ & $\mathbf{p}$ \\
\hline & -0.327 & 0.045 & -0.337 & 0.038 & -0.389 & 0.016 & -0.468 & 0.003 & -0.536 & 0.001 & -0.590 & $<0.001$ \\
\hline $\begin{array}{l}\text { VM } \\
(\mathbf{m V})\end{array}$ & -0.535 & 0.001 & -0.083 & 0.620 & -0.392 & 0.015 & -0.059 & 0.726 & -0.167 & 0.315 & -0.030 & 0.858 \\
\hline $\begin{array}{l}\text { VL } \\
(\mathbf{m V})\end{array}$ & -0.304 & 0.064 & -0.394 & 0.014 & -0.162 & 0.330 & -0.188 & 0.257 & -0.157 & 0.345 & -0.218 & 0.189 \\
\hline $\begin{array}{l}\mathbf{R F} \\
(\mathbf{m V})\end{array}$ & -0.354 & 0.029 & 0.045 & 0.789 & -0.255 & 0.123 & -0.117 & 0.486 & -0.301 & 0.066 & -0.139 & 0.404 \\
\hline
\end{tabular}

\section{Discussion}

When the nueral factors such as motor unit firing rate play a huge role in the first 100 milliseconds of muscle contraction on RTD, after 100 milliseconds the structural factors such as stiffness of a muscle-tendon complex and fiber-type can be considered as the most crucial determinants (Maffiuletti et al., 2016). The Q angle which is structural parameter is an important factor on patellofemoral and tibiofemoral kinematics. Although there is no definite consensus in the literature, the normal Q Angle is valued as $10^{\circ}$ by the Union of American Orthopedics. Comparing torque, work and power outputs, Q angle was found to be negatively related to torque and power (Binder, Brown-Cross, Shamus, \& Davies, 2001; Hahn \& Foldspang, 2007). Our previous study also supports these results (Saç \& Taşmektepligil, 2018). 
Besides that, Morel and his friend clarified that the decreasing on RTD can also cause decrease on torque (Morel et al., 2015).

As a result of this study it is found that the anatomical structural differences in the lower extremity have a negative relationship with RTD when the angular velocity such as 60,120 and, $180 \%$ are considered. It was observed that the correlation coefficients increases as the angular velocity decrease when the angular velocity is considered during the concentric isokinetic contraction. Athletes with a normal Q angle are more likely to have better RTD, than the increased resistance due to reduced angular velocity.

The strength deficit in quadriceps and the patellar maltracking which might have been occurred due to abnormal Q angle values may cause a reduction in RTD. Mirkov and his friends (Mirkov, Nedeljkovic, Milanovic, \& Jaric, 2004), stated that maximal strength capacity and RTD has a significant correlation, in this case our findings can be supported by this statement. In addition, Anderson, Folland and colleagues stated that the correlation coefficients have increased when the contraction time window considered (Andersen \& Aagaard, 2006; Folland, Buckthorpe, \& Hannah, 2014). . In this study, when the torque-time curve was examined in both groups, it was seen that in the first $100 \mathrm{~ms}$ RTD was higher than the rates of 100-200 ms. The difference between the both groups were significant at 120 and $60^{\circ} / \mathrm{s}$ angular velocity. It was also observed that the athletes with a normal Q angle have higher RTDs comparing to the others.

RTD values are known to be related with the reduced EMG values that seen in the first $100 \mathrm{~ms}$ of the contractions (Thorlund, Aagaard, \& Madsen, 2009; Thorlund, Michalsik, Madsen, \& Aagaard, 2008). . Torque development time and RTD, can be affected by the motor unit firing rate and fiber-type (Dotan et al., 2013; Maffiuletti et al., 2016). Even though myoelectrical activity variables do not cause any differences amongst the groups, it is thought that the decrease in terms of the EMG $(0-100 \mathrm{~ms})$ is affecting the RTD values negatively when the ones with the abnormal Q angle are considered.

In myoelectrical activities, there is a correlation 180 and 120\% RTD and Q angle, and this relationship is negative. Possible electromechanical delays between knee extensors known to be caused by patellar maltracking due to structural disorder on Q angle (Cartwright, 2007; Cavazzuti, Merlo, Orlandi, \& Campanini, 2010) might have affected the myoelectric activities. When myoelectric activities between groups are compared, even though the ones with normal Q angle have higher myoelectric activities, this sort of differences was nothing something statistically significant. The reason behind all of this could be that all the participants was trying to apply maximum effort and them having the same sort of sports branch and them having exactly the similar types of fiber-type muscles (Type II). As the participant is encouraged for maximum effort, myoelectrical activities can be observed as the same level like all the motor units fired independently of factors such as type of muscle contraction, angular velocity and sex (Babault, Pousson, Michaut, Ballay, \& Hoecke, 2002; Cramer et al., 2002; Komi \& Buskirk, 1972; Rothstein, Delitto, Sinacore, \& Rose, 1983).

As a result of the study, when the anatomical structure of the lower extremity is taken into consideration, strength training, ballistic training, plyometric training and balance training can be suggested to those with the abnormal Q angle values in order to improve rate of torque development. Quadriceps strength and RTD which is improved by courtesy of these factors can reduce the negative effect of the $\mathrm{Q}$ angle on the knee joints. In addition, to be aware of the structural alignment of the lower extremity, RTD, force capacity and myoelectrical activities can reduce to chance of getting injured. In the future, the results of studies with athletes in different sports branches, sedentary or injury/surgery history may add important findings to literature. The factors affecting structural alignment of lower extremity such as pelvic angle, femoral anteversion angle can be under consideration. The effects of the variables on torque, RTD and electromechanical delay can be examined in the future.

\subsection{Acknowledgements}

This study was presented at 16th International Sport Sciences Congress, Antalya, Turkey, 2018.

\subsection{Declaration of Conflicting Interests}

There is no conflict of interest with any financial or other types of organization regarding the content of the manuscript.

\section{References}

Aagaard, P., Simonsen, E. B., Andersen, J. L., Magnusson, P., \& Dyhre-Poulsen, P. (2002). Increased rate of force development and neural drive of human skeletal muscle following resistance training. Journal of Applied Physiology, 93(4), 1318-1326. https://doi.org/10.1152/japplphysiol.00283.2002

Allen, N. E., Sherrington, C., Canning, C., \& Fung, V. (2010). Reduced muscle power is associated with slower walking velocity and falls in people with Parkinson's disease. Parkinsonism and Related Disorders, 16(4), 261-264. https://doi.org/10.1016/j.parkreldis.2009.12.011 
Andersen, L. L., \& Aagaard, P. (2006). Influence of maximal muscle strength and intrinsic muscle contractile properties on contractile rate of force development. European Journal of Applied Physiology, 96(1), 46-52. https://doi.org/10.1007/s00421-005-0070-z

Babault, N., Pousson, M., Michaut, A., Ballay, Y., \& Hoecke, V. (2002). EMG activity and voluntary activation during knee-extensor concentric torque generation. European Journal of Applied Physiology, 86(6), 541-547. https://doi.org/10.1007/s00421-002-0579-3

Bento, P. C. B., Pereira, G., Ugrinowitsch, C., \& Rodacki, A. L. F. (2010). Peak torque and rate of torque development in elderly with and without fall history. Clinical Biomechanics, 25(5), 450-454. https://doi.org/10.1016/j.clinbiomech.2010.02.002

Binder, D., Brown-Cross, D., Shamus, E., \& Davies, G. (2001). Peak torque, total work and power values when comparing individuals with Q-angle differences. Isokinetics and Exercise Science, 9(1), 27-30. https://doi.org/10.3233/Ies-2001-0060

Blazevich, A. J., Horne, S., Cannavan, D., Coleman, D. R., \& Aagaard, P. (2008). Effect of contraction mode of slow-speed resistance training on the maximum rate of force development in the human quadriceps. Muscle and Nerve, 38(3), 1133-1146. https://doi.org/10.1002/mus.21021

Brattström, H. (1964). Shape of the intercondylar groove normally and in recurrent dislocation of patella: a clinical and x-ray anatomical investigation. Acta Orthopaedica Scandinavica, 35(sup68), 1-148.

Cartwright, A. M. (2007). The influence of Q-angle and gender on the stair-climbing kinetics and kinematics of the knee. University of Waterloo, Canada.

Cavazzuti, L., Merlo, A., Orlandi, F., \& Campanini, I. (2010). Delayed onset of electromyographic activity of vastus medialis obliquus relative to vastus lateralis in subjects with patellofemoral pain syndrome. Gait and Posture, 32(3), 290-295. https://doi.org/10.1016/j.gaitpost.2010.06.025

Chester, R., Smith, T. O., Sweeting, D., Dixon, J., Wood, S., \& Song, F. (2008). The relative timing of VMO and VL in the aetiology of anterior knee pain: a systematic review and meta-analysis. BMC Musculoskeletal Disorders, 9. https://doi.org/10.1186/1471-2474-9-64

Clark, D. J., Patten, C., Reid, K. F., Carabello, R. J., Phillips, E. M., \& Fielding, R. A. (2010). Muscle performance and physical function are associated with voluntary rate of neuromuscular activation in older adults. Journals of Gerontology Series A: Biomedical Sciences and Medical Sciences, 66(1), 115-121. https://doi.org/10.1093/gerona/glq153

Cramer, J. T., Housh, T. J., Weir, J. P., Johnson, G. O., Ebersole, K. T., Perry, S. R., \& Bull, A. J. (2002). Power output, mechanomyographic, and electromyographic responses to maximal, concentric, isokinetic muscle actions in men and women. Journal of Strength and Conditioning Research, 16(3), 399-408.

Dotan, R., Mitchell, C., Cohen, R., Gabriel, D., Klentrou, P., \& Falk, B. (2013). Child-adult differences in the kinetics of torque development. Journal of Sports Sciences, 31(9), 945-953.

Folland, J. P., Buckthorpe, M. W., \& Hannah, R. (2014). Human capacity for explosive force production: Neural and contractile determinants. Scandinavian Journal of Medicine and Science in Sports, 24(6), 894-906. https://doi.org/10.1111/sms.12131

Freire, B., Dias, C. P., Oliveira, L. S., Goulart, N., Lemos, F. A., Becker, J., . . Vaz, M. A. (2015). Rate of force development and torque production assessment in spastic stroke survivors. Revista Brasileira de Cineantropometria \& Desempenho Humano, 17(3), 328-336.

Hahn, T., \& Foldspang, A. (2007). The Q angle and sport. Scandinavian Journal of Medicine \& Science in Sports, 7(1), 43-48.

Harridge, S. D. R., Bottinelli, R., Canepari, M., Pellegrino, M. A., Reggiani, C., Esbjornsson, M., \& Saltin, B. (1996). Whole-muscle and single-fibre contractile properties and myosin heavy chain isoforms in humans. Pflugers Archiv-European Journal of Physiology, 432(5), 913-920.

Hermens, H. J., Freriks, B., Disselhorst-Klug, C., \& Rau, G. (2000). Development of recommendations for SEMG sensors and sensor placement procedures. Journal of Electromyography and Kinesiology, 10(5), 361-374. https://doi.org/10.1016/S1050-6411(00)00027-4

Holsgaard-Larsen, A., Caserotti, P., Puggaard, L., \& Aagaard, P. (2011). Stair-ascent performance in elderly women: effect of explosive strength training. Journal of Aging and Physical Activity, 19(2), 117-136. 
Komi, P. V., \& Buskirk, E. R. (1972). Effect of eccentric and concentric muscle conditioning on tension and electrical-activity of human muscle. Ergonomics, 15(4). https://doi.org/10.1080/00140137208924444

Laffaye, G., \& Wagner, P. (2013). Eccentric rate of force development determines jumping performance. Computer Methods in Biomechanics and Biomedical Engineering, 16, 82-83. https://doi.org/10.1080/10255842.2013.815839

Livingston, L. A. (1998). The quadriceps angle: A review of the literature. Journal of Orthopedic and Sports Physical Therapy, 28(2), 105-109. https://doi.org/10.2519/jospt.1998.28.2.105

Maffiuletti, N. A., Aagaard, P., Blazevich, A. J., Folland, J., Tillin, N., \& Duchateau, J. (2016). Rate of force development: physiological and methodological considerations. European Journal of Applied Physiology, 116(6), 1091-1116. https://doi.org/10.1007/s00421-016-3346-6

Mirkov, D. M., Nedeljkovic, A., Milanovic, S., \& Jaric, S. (2004). Muscle strength testing: evaluation of tests of explosive force production. European Journal of Applied Physiology, 91(2-3), 147-154. https://doi.org/10.1007/s00421-003-0946-8

Morel, B., Rouffet, D. M., Saboul, D., Rota, S., Clemencon, M., \& Hautier, C. A. (2015). Peak torque and rate of torque development influence on repeated maximal exercise performance: contractile and neural contributions. Plos One, 10(4). https://doi.org/10.1371/journal.pone.0119719

Nuzzo, J. L., McBride, J. M., Cormie, P., \& McCaulley, G. O. (2008). Relationship between countermovement jump performance and multijoint isometric and dynamic tests of strength. Journal of Strength and Conditioning Research, 22(3), 699-707. https://doi.org/10.1519/JSC.0b013e31816d5eda

Rothstein, J. M., Delitto, A., Sinacore, D. R., \& Rose, S. J. (1983). Electromyographic, peak torque, and power relationships during isokinetic movement. Physical Therapy, 63(6), 926-933.

Saç, A., \& Taşmektepligil, M. Y. (2018). Correlation between the Q angle and the isokinetic knee strength and muscle activity. Turkish Journal of Physical Medicine and Rehabilitation.

Slawinski, J., Bonnefoy, A., Leveque, J. M., Ontanon, G., Riquet, A., Dumas, R., \& Cheze, L. (2010). Kinematic and kinetic comparisons of elite and well-trained sprinters during sprint start. Journal of Strength and Conditioning Research, 24(4), 896-905. https://doi.org/10.1519/JSC.0b013e3181ad3448

Thorlund, J. B., Aagaard, P., \& Madsen, K. (2009). Rapid muscle force capacity changes after soccer match play. International Journal of Sports Medicine, 30(4), 273-278. https://doi.org/10.1055/s-0028-1104587

Thorlund, J. B., Michalsik, L. B., Madsen, K., \& Aagaard, P. (2008). Acute fatigue-induced changes in muscle mechanical properties and neuromuscular activity in elite handball players following a handball match. Scandinavian Journal of Medicine and Science in Sports, 18(4), 462-472. https://doi.org/10.1111/j.1600-0838.2007.00710.x

Thorstensson, A., Karlsson, J., Vitasalo, J. H. T., Luhtanen, P., \& Komi, P. V. (1976). Effect of strength training on EMG of human skeletal-muscle. Acta Physiologica Scandinavica, 98(2), 232-236. https://doi.org/10.1111/j.1748-1716.1976.tb00241.x

Tillin, N. A., Pain, M. T. G., \& Folland, J. (2013). Explosive force production during isometric squats correlates with athletic performance in rugby union players. Journal of Sports Sciences, 31(1), 66-76. https://doi.org/10.1080/02640414.2012.720704

Witvrouw, E., Lysens, R., Bellemans, J., Cambier, D., \& Vanderstraeten, G. (2000). Intrinsic risk factors for the development of anterior knee pain in an athletic population a two-year prospective study. The American Journal of Sports Medicine, 28(4), 480-489. https://doi.org/10.1177/03635465000280040701

\section{Copyrights}

Copyright for this article is retained by the author(s), with first publication rights granted to the journal.

This is an open-access article distributed under the terms and conditions of the Creative Commons Attribution license which permits unrestricted use, distribution, and reproduction in any medium, provided the original work is properly cited. 